\title{
Os escritos episcopais \\ e monásticos \\ enquanto vestígios das \\ movimentações \\ políticas e sociais de \\ Folcuíno de Lobbes \\ (935-990) e Ratério de \\ Verona (890-974)
}

\section{Vitor Boldrini *}

DOI: 10.11606/issn.2318-8855.v10i2p518-552

Resumo: A temática central do presente artigo é a discussão sobre as formas dos indivíduos ligados à Igreja se situarem politicamente ao longo do século $X$, período este marcado pelo desmembramento do Império Carolíngio. Para tanto, elegemos algumas obras do monge Folcuíno de Lobbes e do abade e bispo Ratério de Verona. Compartilhando por vezes experiências em comum, ambos estiveram diretamente envolvidos em disputas relativas à construção da autoridade sobre locais muito prestigiosos, como bispados e monastérios. Consideramos que os textos nos permitem elaborar hipóteses a respeito dos modos pelos quais eles procuraram defender seus respectivos interesses políticos. Assim, ao estabelecer uma estreita conexão entre os documentos e os momentos particulares das trajetórias dos seus autores, é possível observar como a edificação dos poderes no período dependia muito mais de relações interpessoais, pautadas por alianças políticas multifacetadas e redes de fidelidade mútuas, do que de papéis desempenhados em instituições centralizadas. Os caminhos trilhados por Folcuíno e Ratério revelam, enfim, algumas das atribuições de dois eclesiásticos, que recorriam a estratégias discursivas na defesa de valores sociais específicos.

Palavras-chave: Autoridade, Igreja, Fontes Episcopais, Fontes Monásticas

* Membro do Laboratório de Estudos Medievais (LEME) - Núcleo UNICAMP. E-mail para contato: . Agradeço à Profa. Dra. Néri de Barros Almeida, minha orientadora desde o início de meus trabalhos de Iniciação Científica, em 2017. Sou grato também pelas atentas leituras deste texto que foram feitas por André Mateus Pupin, Diego Nascimento e Nanci Martinelli. Por fim, agradeço à Fundação de Amparo à Pesquisa do Estado de São Paulo (FAPESP) pelo financiamento da minha atual pesquisa, cujos primeiros resultados foram aqui reunidos. 


\section{O poder na Idade Média}

Vitor Boldrini

\section{Contextualização e definição da problemática}

O ano de 840 foi marcado pela morte de Luís, o Piedoso, sucessor de Carlos Magno no trono do Império Carolíngio. Três anos depois, seus herdeiros estabeleceram a divisão tripla do reino: a França Ocidental, sob responsabilidade de Carlos, o Calvo; a França Média, administrada por Lotário; e a França Oriental, delegada a Luís, o Germânico (imagem 1).

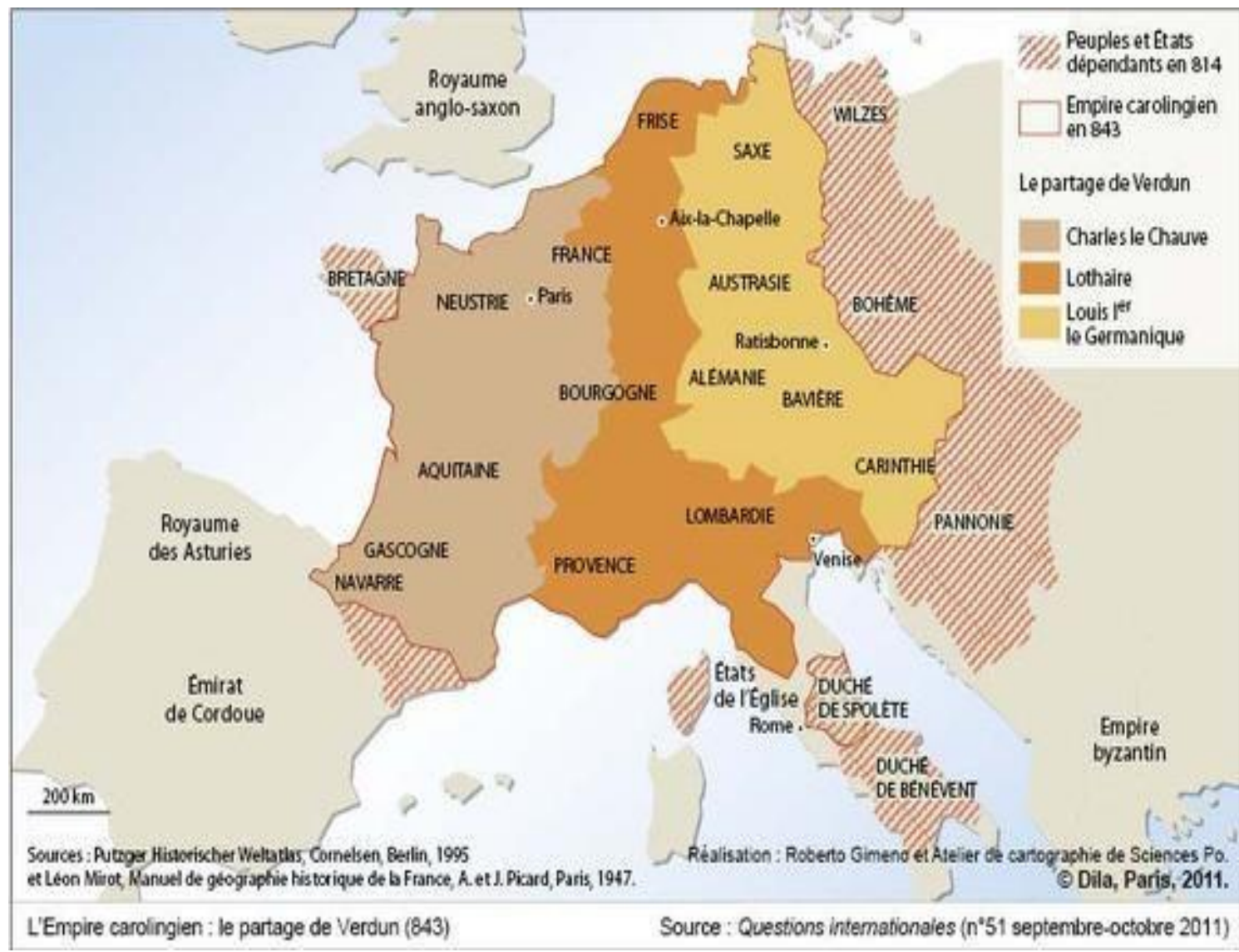

Imagem 1: As divisões do Império Carolíngio após o Tratado de Verdun, em 843.

Fonte: (GIMENO, 2011). 


\section{O poder na Idade Média}

Os escritos episcopais e monásticos enquanto vestígios das movimentações políticas e sociais de Folcuíno de Lobbes (935-990) e Ratério de Verona (890-974)

Essa partilha foi apenas a primeira, de muitas outras ocorridas a partir da segunda metade do século IX, que sinalizam tendências de descentralização política (JÉGOU; PANFILI, 2018, p. 12). Se antes os reis exerciam influência em boa parte do território com relativa estabilidade, a passagem do século IX ao $\mathrm{X}$ significou $\mathrm{O}$ fortalecimento de autoridades locais, como duques e condes, que passaram a cumprir, no âmbito regional, prerrogativas fiscais, judiciais e militares, outrora reservadas ao rei carolíngio. Esse período representou, de fato, a ascensão política de certas famílias aristocráticas, como os Guilhermidas e os Robertianos (imagem 2).

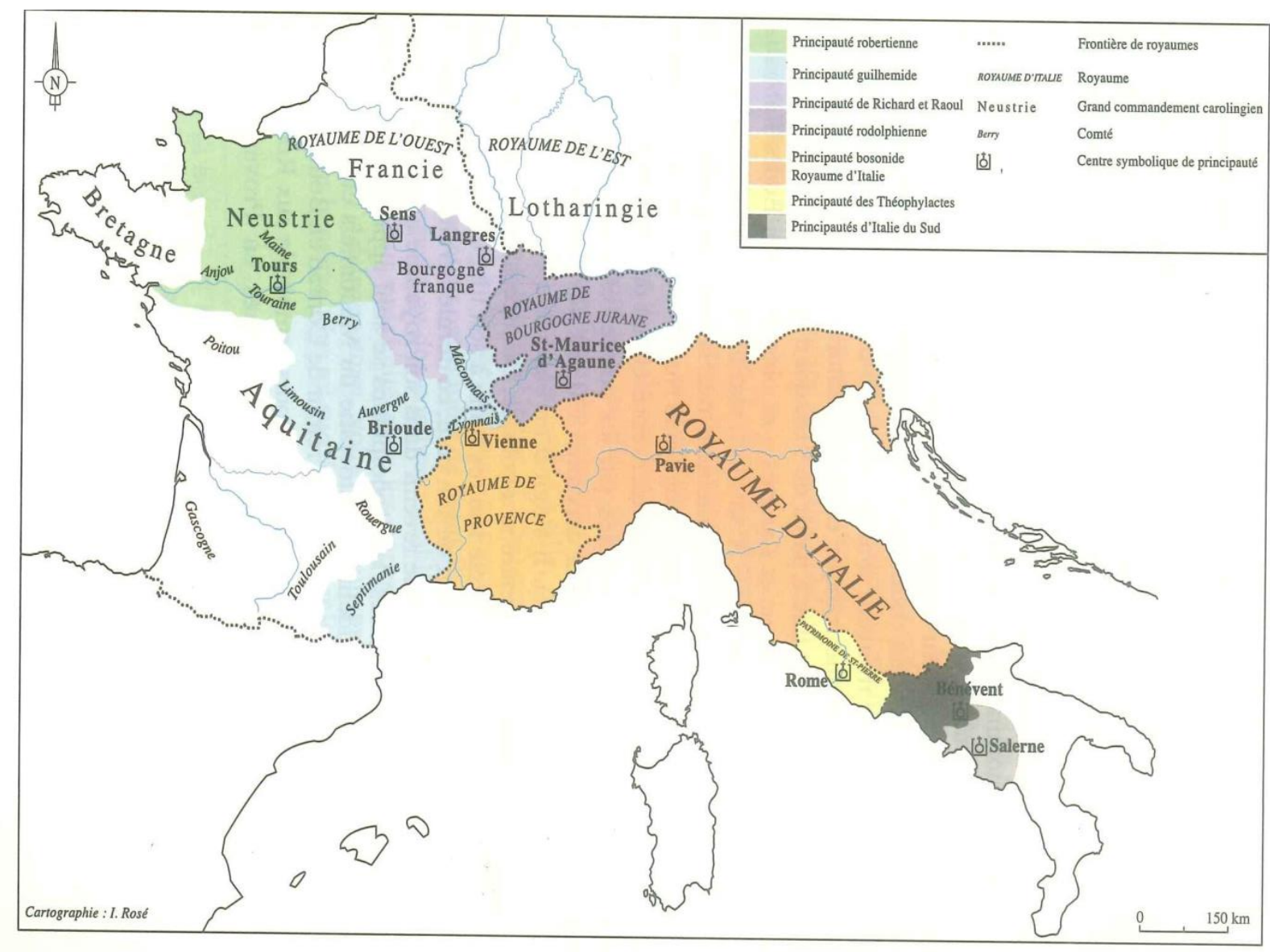

Imagem 2: Os condados, principados territoriais e reinos entre os séculos IX e X. Fonte: (ROSÉ, 2008). 


\section{O poder na Idade Média}

Vitor Boldrini

Dentre as prerrogativas anteriormente restritas ao rei que passaram a ser executadas por outros grupos, podem ser citadas a nomeação de abades e a restauração ou fundação de novos monastérios. Após a morte de Carlos Magno, os laicos mais proeminentes começaram a controlar essas atribuições de modo mais autônomo (MAZEL, 2011, p. 49). No Principado dos Guilhermidas, por exemplo, a iniciativa do Duque da Aquitânia, Guilherme, o Piedoso, foi imprescindível na construção daquele que se tornaria um dos centros monásticos mais importantes da Cristandade, a abadia de Cluny (IOGNA-PRATT, 2006), conforme atestado pela carta de fundação: “Eu [Guilherme] dou tudo isso para que um monastério regular seja construído em Cluny em nome da honra dos apóstolos Pedro e Paulo. Os monges ali deverão viver e se congregar segundo a Regra de São Bento, mantendo e possuindo para sempre todas essas coisas concedidas" (HENDERSON, 1910, p. 331, tradução própria) ${ }^{1}$.

No Sacro-Império Romano Germânico, proveniente da França Oriental, sabemos que, em muitas oportunidades, coube ao Imperador Germânico designar abades e bispos. Por exemplo, em 953, Bruno, irmão do Imperador Oto I, foi diretamente por ele nomeado Arcebispo de Colônia e Duque da Lotaríngia (PARISSE, 1983, p. 96).

Em síntese, notamos como as medidas relativas ao controle de monastérios e dioceses se tornaram mais diversificadas, isto é, menos dependentes de um rei, que determinava ele próprio a política desses estabelecimentos. No período de declínio

\footnotetext{
${ }^{1}$ No original: "I give these things, moreover, with this understanding, that in Cluny a regular monastery shall be constructed in honour of the holy apostles Peter and Paul, and that there the monks shall congregate and live according to the rule of St. Benedict, and that they shall possess, hold, have and order these same things unto all time". Daqui em diante, todas as citações em língua estrangeira - cujas formas originais foram mantidas nas notas de rodapé - serão incorporadas no corpo do texto a partir de traduções próprias.
} 


\section{O poder na Idade Média}

Os escritos episcopais e monásticos enquanto vestígios das movimentações políticas e sociais de Folcuíno de Lobbes (935-990) e Ratério de Verona (890-974)

do Reino Carolíngio, os papéis das autoridades regionais foram acentuados, o que fez com que os locais sagrados se tornassem objetos de acirradas competições (DEPREUX; BOURGARD; LE JAN, 2015, p. 5-16). As histórias das abadias e dos bispados no século $X$, portanto, estão conectadas de modo estreito à consolidação do poder de numerosos agentes sociais, como duques, condes, viscondes e imperadores germânicos, que se aproveitaram da fragilidade dos reis carolíngios para ampliar sua dominação.

Diante desse novo mosaico de forças políticas heterogêneas e complexas, seria precipitado argumentar que a Igreja "estivera nas mãos dos laicos" (DUMAS, 1945), como se os membros da instituição eclesiástica estivessem totalmente à mercê dos conflitos entre aristocratas, desprovidos assim de atuação política. Na realidade, tendo combinado os poderes espiritual e temporal, os homens da Igreja demonstraram adaptação e capacidade de interferência nas evoluções sociais e políticas de seus tempos. Os estudos mais recentes sobre a sociedade senhorial dos séculos X e XI têm procurado enfatizar o lugar de destaque ocupado pelos membros da instituição eclesiástica (LAUWERS, 2009, p. 288). Outros historiadores vão ainda mais longe, defendendo que a Igreja era nada menos do que a espinha dorsal da Idade Média (GUERREAU, 2001, p. 28).

Para que possamos desenvolver estudos sobre o exercício da autoridade no período, é crucial, então, levar em consideração elementos como o lugar dos clérigos na sociedade, a construção e a evolução de entidades políticas e os processos de regulação social. A partir dessas ferramentas, recorremos à análise das fontes disponíveis, que nos permitem elaborar hipóteses sobre casos particulares. Sem completar as lacunas de textos com generalidades e paralelos imprecisos, o estudo 


\section{O poder na Idade Média}

Vitor Boldrini

amplo e concentrado dos documentos - seu autor, contexto de escrita, motivações no momento da produção, etc. -, esclarece elementos típicos de situações regionais.

O exame de algumas das obras compostas pelo monge Folcuíno e pelo abade e bispo Ratério pressupõe realocá-las nos momentos específicos das trajetórias desses dois homens, verificando, assim, os mecanismos por meio dos quais eles visavam assegurar uma posição social privilegiada.

\section{A circulação de Ratério: entre a Lotaríngia e a Península Itálica (890-961)}

Ratério nasceu em 890 na Diocese de Liège (sede episcopal representada em verde no mapa abaixo, na região da "Francia Media"). Com apenas nove anos de idade, ele se tornou oblato na abadia de Lobbes (situada a poucos quilômetros a oeste de Liège, indicada em laranja no mapa), conhecida pelo seu "alto nível de formação intelectual e pelas qualidades de seu scriptorium" (DIERKENS, 2013, p. 279)². Até 920, Ratério permaneceu nesse local e foi lá educado segundo valores da cultura monástica.

\footnotetext{
${ }^{2}$ No original: "I'abbaye de Lobbes était déjà réputée pour son haut niveau de formation intellectuelle et pour les qualités de son scriptorum".
} 


\section{O poder na Idade Média}

Os escritos episcopais e monásticos enquanto vestígios das movimentações políticas e sociais de Folcuíno de Lobbes (935-990) e Ratério de Verona (890-974)

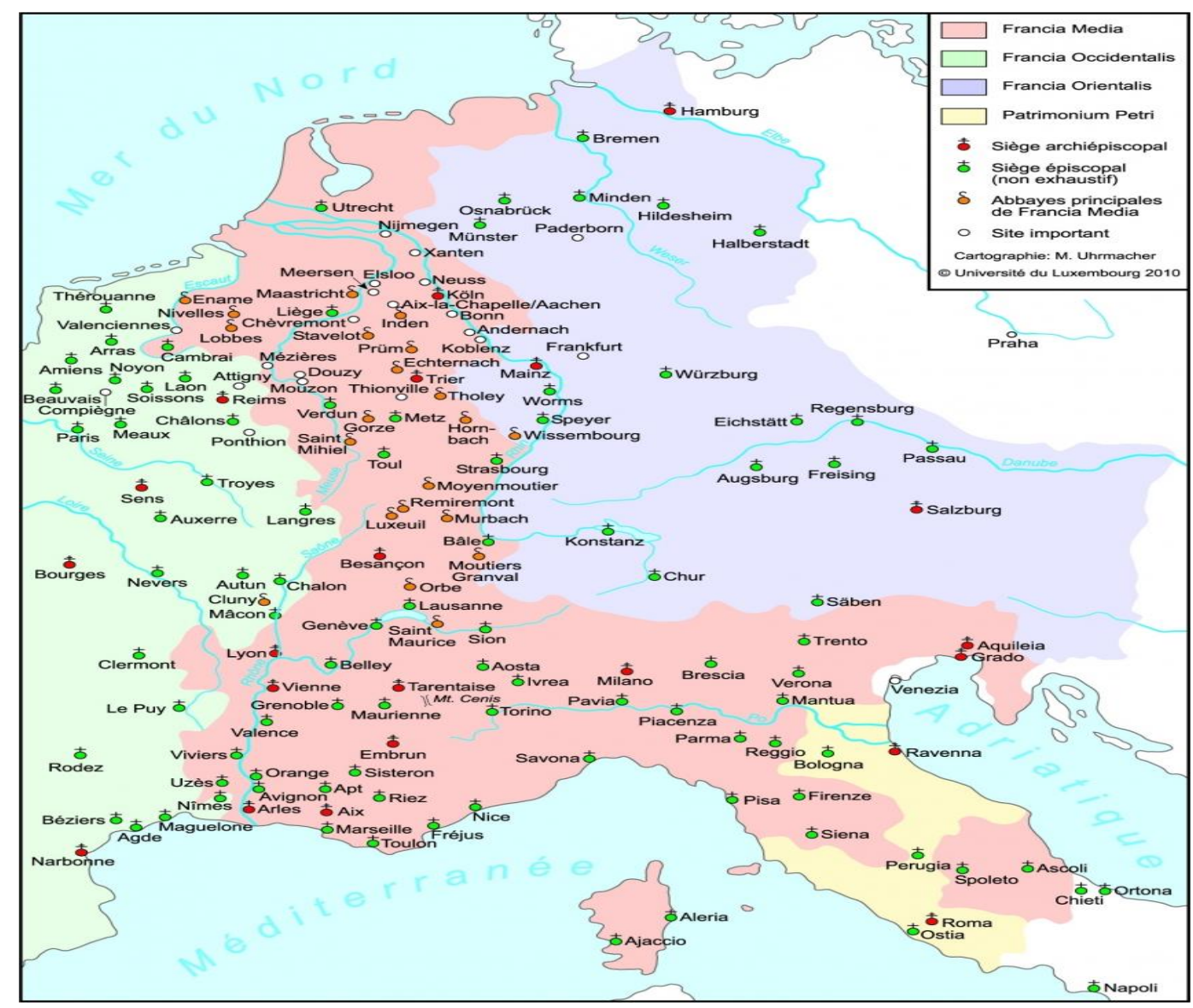

Imagem 3: Abadias e sedes episcopais no início do século X. Fonte: (UHRMACHER, 2011)

Porém, a morte do bispo de Liège, Estevão, em 19 de maio de 920, provocou uma grave crise de sucessão. Afrontaram-se, de um lado, o clérigo Hilduíno e, de outro, o abade de Prüm, Ricário. A querela era de enorme importância para Ratério e sua comunidade monástica, pois, desde 889, a Diocese deixou de estar institucionalmente ligada ao Rei Carolíngio e passou a ser controlada pelo bispo de Liège, que exercia também o cargo de abade em Lobbes (DIERKENS, 1985, p. 111). 0 final da disputa foi assinalado pela bula papal de João X, que nomeou Ricário como o novo bispo, em 920 (ZIMMERMANN, 1984, p. 19). Hilduíno, então, parte para o exílio 


\section{O poder na Idade Média}

Vitor Boldrini

na Península Itálica acompanhado de Ratério, um de seus principais aliados. Em agosto de 931, quando Hilduíno foi nomeado bispo de Milão, o Bispado de Verona ficou vago, e Ratério o ocupou até fevereiro de 934 (sinalizado ao norte da Península na imagem acima). Ele então se envolveu num conflito com o Rei da Itália, Hugo, que o havia auxiliado no início do seu bispado. Essa querela resultou na prisão de Ratério em Pávia, uma sede episcopal vizinha, onde ele iniciou a escrita de "Praeloquia", a primeira obra aqui considerada.

\subsection{Praeloquia: descrever o mundo, teorizar a sociedade.}

Também conhecido pelos historiadores como “Meditações de um Homem no Exílio" (RENSWOUDE, 2010, p. 227)³, Praeloquia é um livro de contemplações pessoais e de conselhos morais que Ratério direciona a todas as camadas e classes da sociedade, de soldados a reis, de servos a bispos. Esse amplo esforço de reflexão oferece aos historiadores uma obra valiosíssima, na qual estão presentes as maneiras próprias do autor de dar sentido ao mundo. Há poucos indícios sobre a difusão do livro e o seu consequente impacto social (DOLBEAU, 2016, p. 133-151). Entretanto, alguns elementos expostos deixam claras as representações feitas por esse homem aqui já gozando de uma dupla identidade, monástica e episcopal -, que expressa no livro determinadas perspectivas sobre as dinâmicas ideais de funcionamento da sociedade, bem como as suas subsequentes relações de poder.

No prefácio, Ratério se define como um atleta de Deus no mundo, disposto a empreender, nos campos político e social, uma "luta contra o Diabo" (KURDZIEL, 2010, p. 313) ${ }^{4}$. Esses discursos são provenientes das Sagradas Escrituras e dos escritos dos

\footnotetext{
${ }^{3}$ No original: "Meditations of a Man in Exile".

${ }^{4}$ No original: "L'agon y est toujours compris comme le combat de l'athlète de Dieu contre l'adversaire par excellence, le diable".
} 


\section{O poder na Idade Média}

Os escritos episcopais e monásticos enquanto vestígios das movimentações políticas e sociais de Folcuíno de Lobbes (935-990) e Ratério de Verona (890-974) Pais da Igreja, conforme indicam as numerosas citações da obra Moralia in lob, de Gregório, o Grande (KURDZIEL, 2010, p. 316). A originalidade de Praeloquia reside no fato desse combate ultrapassar o quadro espiritual: para Ratério, a sua luta compreende também o mundo secular. Portanto, ao se reivindicar "Agonisticus" (DOLBEAU, 1985, p. 552), um combatente a serviço de Deus, destacamos a dupla motivação do autor na escrita desse texto: no campo espiritual, ele visa batalhar contra as paixões inspiradas pelo Diabo, por meio da apologia aos valores advindos de sua formação monástica, entre os quais a castidade e a recusa ao estilo de vida luxuoso e pecador; no âmbito terreno, Ratério se põe como um guerreiro "athleta pugnacissime" (REID, 1976, p. 5), que se posiciona contra seus inimigos, entre eles o Rei da Itália, Hugo, aquele que, como vimos acima, foi responsável pela destituição de Ratério do Bispado de Verona e pela sua prisão subsequente.

Ao longo da obra, é patente o cuidado do autor em conceber sermões destinados aos "diversos estados do mundo" (LE JAN, 2008, p. 14)5. No primeiro livro, por exemplo, ele visa, em 19 parágrafos, descrever todos os elementos que compõem a sociedade, dividindo-a em múltiplos critérios, como as categorias socioprofissionais, o estatuto ou a riqueza e o estado civil, estando todos esses grupos, entretanto, permeados pelas suas obrigações cristãs. Seguindo a retórica do apóstolo Paulo, Ratério buscou abarcar a totalidade dos fiéis enquanto um conjunto definidor da Cristandade, valendo-se, para tanto, de parâmetros flexíveis e, por vezes, genéricos, que são próprios do seu modo de enxergar a sociedade.

A discussão é mais condensada no terceiro livro, no qual Ratério discute as relações do bispo com o Rei. O poder sacerdotal consiste na capacidade de unir e

\footnotetext{
${ }^{5}$ No original: "les divers états du monde".
} 


\section{O poder na Idade Média}

Vitor Boldrini

dissolver, sem ter a obrigação, em nenhum caso, de se sujeitar ao Rei. Atuando como o representante de Deus numa sociedade vista como uma coletividade eclesiástica, o poder episcopal "deve prevalecer sobre todos [inclusive sobre o Rei], que está acima apenas de alguns" (REID, 1976, p. 84) ${ }^{6}$. Podemos inferir que essa argumentação reflete a perda por Ratério do Bispado de Verona, após a disputa com Hugo, o Rei da Itália. A interpretação do autor, exaltando a função episcopal em detrimento dos atributos reais, está estreitamente conectada com suas lutas políticas do presente.

No capítulo 22 do mesmo livro, ele conclui de modo adensado uma "divisão tripla dos filhos da Igreja" (REID, 1976, p. 95)7 (ver imagem 4 abaixo):

Todos, eu afirmo, são filhos da Igreja (filli Ecclesiae), mas só alguns são filhos do Senhor (de sorte Domini). Estes são os clérigos (clerici) e monges (monachi), conhecidos como servidores da Igreja e "servos" (confamuli) dos bispos (episcopi). Os demais são trabalhadores (laboratores), servos (servi) ou livres (liberi), ou cavaleiros do reino (milites regni) (REID, 1976, p. 95) ${ }^{8}$.

O esquema proposto não oferece uma visão omnicompreensiva da sociedade do período. O esforço teórico de Ratério é, na verdade, uma resposta particular pautada por sua dupla identidade, episcopal e monástica. O discurso revela as suas aspirações pessoais e os seus modos de definir as hierarquias e o funcionamento ideal de uma sociedade cristã. O modelo da tripartição, as referências bíblicas e os debates mobilizados a partir dos Pais da Igreja simbolizam a formação monástica que

\footnotetext{
${ }^{6}$ No original: "Nam tu super aliquos, illi super te et super omnes".

${ }^{7}$ No original: "Trifaria divisio filiorum Ecclesiae".

${ }^{8}$ No original: "Omnes, inquam, Ecclesiae filii aut de sorte sunt Domini et appellantur clerici et monachi, aut Ecclesiae famuli, episcopi vero confamuli, aut laboratores, servi et liberi, aut milites regni".
} 


\section{O poder na Idade Média}

Os escritos episcopais e monásticos enquanto vestígios das movimentações políticas e sociais de Folcuíno de Lobbes (935-990) e Ratério de Verona (890-974) ele recebeu, durante o período em que foi oblato no monastério de Lobbes. Com esses elementos, Praeloquia anuncia um suporte conceitual criado pelo autor para reforçar as próprias armas de luta política e pessoal. Por meio desse texto, Ratério demonstra que não era um homem da Igreja que ignorava as metamorfoses referentes ao exercício da autoridade. A análise da fonte sugere, de maneira oposta, que ele estava imbricado nas mais áridas querelas do Bispado de Verona: as representações feitas em Praeloquia repercutem, em grande medida, o momento delicado pelo qual ele passava após sua prisão em Pávia.

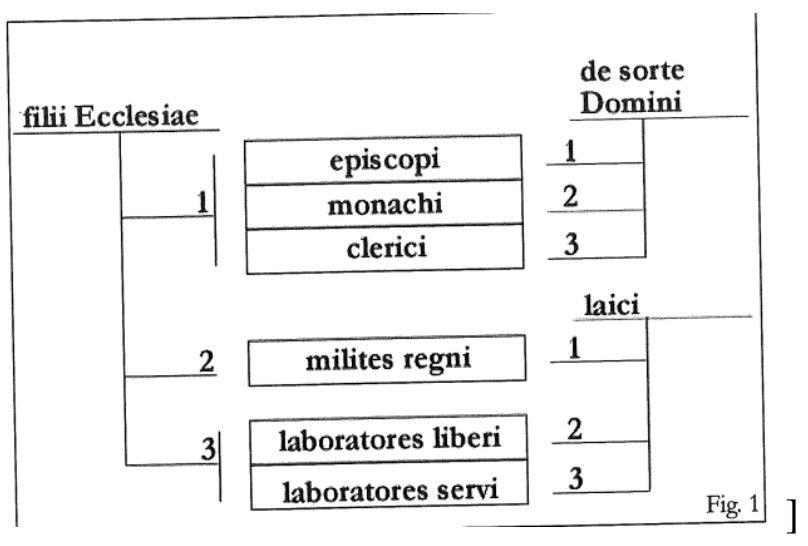

Imagem 4: A divisão tripla da sociedade, segundo Ratério.

Fonte: (VIGNODELLI, 2007). 


\section{O poder na Idade Média}

Vitor Boldrini

\subsection{Ratério, bispo de Liège (953-954)}

Em 946, sete anos após sua soltura, Ratério retomou a Sede Episcopal em Verona, mas a instabilidade local o impediu de lá permanecer por muito tempo: logo, em 948, ele abandonou a Diocese e voltou para a Lotaríngia. Após o violento conflito pela sucessão do bispo Estevão, o Bispado de Liège conheceu certa estabilidade política em razão de sua integração ao Império Germânico, em 925. Diante desse novo contexto favorável e dispondo ainda do apoio do Rei Oto I, Ratério foi por ele nomeado, em 25 de setembro de 953, como o novo bispo de Liège - a Sede Episcopal estava vaga desde a morte de Faraberto, ocorrida no mês precedente -, tornando-se, consequentemente, abade de Lobbes.

Destacamos que, mesmo durante os anos em que foi bispo de Verona, Ratério não abandonou completamente a concepção monástica obtida nos primeiros anos de formação enquanto oblato. Entre 939 e 945, ele redigiu a Vita Ursmari tertia, uma hagiografia referente ao Santo Ursmar, um dos fundadores da abadia de Lobbes no século VII (DIERKENS, 2013, p. 286). O texto foi enviado à comunidade monástica e serviu como um estímulo para a criação de uma identidade comum a partir do culto a esse Santo. Em vista disso, o retorno de Ratério à Lotaríngia não é nenhuma surpresa: mesmo tendo se afastado temporariamente, ele manteve contatos que the permitiram regressar posteriormente a Lobbes.

Embora tenha sido bem recebido pelos monges, a aristocracia local reagiu à sua nomeação, que consagrava o controle dos Imperadores Otonianos sobre a região, em detrimento da autonomia política de duques e outras figuras de destaque. Na Noite de Natal de 954, o conde Reginaldo III destituiu Ratério do Bispado, escolhendo seu sobrinho Balderico como sucessor. Pela proximidade com a Corte dos 


\section{O poder na Idade Média}

\section{Os escritos episcopais e monásticos enquanto vestígios das movimentações políticas e sociais de Folcuíno de Lobbes (935-990) e Ratério de Verona (890-974)}

Imperadores Germânicos, Ratério encontrou refúgio em Mainz, junto ao arcebispo Guilherme, um dos filhos de Oto I. Foi aí que ele escreveu a segunda obra analisada, o tratado Phrenesis, entre 955 e 956.

Usando a terceira pessoa, Ratério expôs no texto elementos relativos à sua conturbada experiência política mais recente. Os primeiros parágrafos do documento buscam reforçar a legitimidade de seu bispado em Liège:

E no domingo seguinte [25 de setembro de 953], ele [Ratério] foi eleito bispo pela congregação da Igreja de Liège, composta por outros 7 bispos, dois dos quais eram arcebispos, a saber: Bruno, arcebispo de Colônia, e Roberto, arcebispo de Trier. Os bispos restantes eram Balderico de Utrecht, Hildibaldo de Munster, Drogo de Osnabrück, Berengário de Verdun e Fulberto de Cambrai. Tudo passou de acordo com os decretos e seguindo o exemplo daqueles que fizeram o mesmo no passado. Ele foi aclamado sob grande aplauso por toda a congregação presente e solenemente entronizado. (ROBERTS, 2019, p. 124) .

Para enaltecer o sucesso de sua nomeação na Diocese de Liège, Ratério cita o apoio recebido de outros ilustríssimos bispos de sua época, entre os quais se destaca Bruno, arcebispo de Colônia. O fato de sublinhar uma estreita vinculação do seu bispado com a Corte Imperial demonstra a tentativa do autor de marcar a validade do novo cargo. Ratério menciona, ainda, a suposta aprovação recebida por parte de toda

\footnotetext{
${ }^{9}$ No original: "And on the following Sunday [25 September], he was again elected by that congregation, that is, of the church of Liège, by seven fellow-bishops, of whom two were archbishops, Brun [of Cologne] and Robert [of Trier], and the rest bishops, Balderic [of Utrecht], Hildibald [of Munster], Drogo [of Osnabrück], Berengar [of Verdun], and Fulbert [of Cambrai], in accordance with the decretals and following the precedent example of several to whom this had happened in times past. He was acclaimed with great applause by the whole congregation which was present, and solemnly enthroned".
} 


\section{O poder na Idade Média}

Vitor Boldrini

a congregação da Igreja de Liège, bem como as solenidades no momento em que foi entronizado, e também a continuidade de seu bispado em relação às práticas de seus predecessores, justificando, assim, sua função episcopal por ele considerada legítima. A formulação - por meio da fonte - desse quadro de estabilidade na Diocese, elaborada imediatamente após o autor tê-la perdido, nos permite inferir que Ratério buscou desqualificar e reprovar a revolta conduzida por Reginaldo III, que o forçou a abandonar Liège. Essa passagem, portanto, testemunha o seu posicionamento e mesmo sua incredulidade diante dos eventos ocorridos há alguns meses.

Na sequência, ele ainda critica a negligência do arcebispo Bruno de Colônia que, "por sua timidez, não pôde encontrar ninguém entre os amigos e defensores de Ratério para ajudar em oposição a essa ação [o golpe planejado por Reginaldo III e Balderico]" (ROBERTS, 2019, p. 124) ${ }^{10}$, algo que poderia ter evitado a sua deposição.

Para explicar o título "Loucura" (Phrenesis), o autor faz referência a seus dois principais inimigos, Balderico e o arcebispo de Trier, Roberto - visto por ele como o homem que orquestrou a revolta -, tendo ambos a qualificação de phreneticus (louco). Assim, a escrita da obra está bastante conectada com as experiências políticas - para não dizer os fracassos - de Ratério em Liège, glorificando as suas atribuições, ao mesmo tempo em que ele desqualifica os responsáveis pela sua retirada.

Num outro trecho do documento também muito elucidativo, Ratério reitera alguns dos direitos dos bispos, insinuando que sua deposição foi completamente ilegítima:

\footnotetext{
${ }^{10}$ No original: "because of the timidity of the king's brother [Brun], could find no one among Bishop Rather's friends and retainers to help in opposing this action".
} 


\title{
O poder na Idade Média
}

\author{
Os escritos episcopais e monásticos enquanto vestígios das movimentações \\ políticas e sociais de Folcuíno de Lobbes (935-990) e Ratério de Verona (890-974)
}

Por meio desses exemplos, fica claro que quando algum bispo é legalmente nomeado, ele não pode ser removido por sua posição, enquanto a defesa da ordem permanecer segura. Uma vez aceito, ele não pode ser deslocado de sua posição. Portanto, não existe força suficiente para destronar um bispo; os elogios e as censuras dos cristãos, as demandas e as proibições da lei concordam em igual peso e protegem-no igualmente (ROBERTS, 2019, p. $129)^{11}$.

Os trechos selecionados sugerem que o autor não era um homem da Igreja preocupado apenas com sua salvação espiritual. A reivindicação da Sé Episcopal de Liège influenciou o teor de seus discursos, despertando, consequentemente, seu enorme interesse pelas redefinições das autoridades locais. Isso mostra, em última instância, que os aspectos políticos e religiosos estavam acoplados um ao outro no período: essas duas esferas devem ser trabalhadas, então, considerando a mencionada imbricação mútua.

A hegemonia do grupo que comandou a sublevação logo declinou. Reginaldo III foi condenado pelo arcebispo Bruno de Colônia ao exílio, em 958, e Balderico morreu em 959. Embora seja razoável presumir que o bispo anterior à revolta deveria ter recuperado sua função, isso não ocorreu. Ao acompanhar Oto I em uma viagem à Península Itálica em 961, Ratério foi reinstalado pelo Imperador na Diocese de Verona. Um ano antes, ele já havia manifestado seu desinteresse pela retomada do Bispado de Liège, numa carta enviada a Bruno de Colônia, mesmo após o

\footnotetext{
${ }^{11}$ No original: "From these examples it is quite clear that if anyone lawfully promoted, he cannot legally be removed from his position, while the defence of the order stands secure. For once he has accepted it, a bishop cannot be driven from his position. By this precedent, there is no force strong enough to dislodge a bishop; reason, the praise and censure of Christians, the demands and prohibitions of the law, agree with equal weight and equally protect him".
} 


\section{O poder na Idade Média}

Vitor Boldrini

afastamento dos revoltosos (REID, 1994, p. 318-319). Assim sendo, Eráclio é nomeado novo bispo.

Conforme citamos anteriormente, aquele que exercia a função episcopal em Liège era, simultaneamente, o abade de Lobbes. Entretanto, a ascensão de Eráclio mudou essa dinâmica: a partir de então, o bispo deixou de acumular as atribuições monástica e episcopal e passou a nomear outros indivíduos para o cargo. Por isso, ele designou Aletrão como o novo abade de Lobbes, em 961 (DIERKENS, 1984, p. 119). No entanto, suas debilitadas condições de saúde impediram que tivesse um abaciado mais longo: ele faleceu apenas quatro anos depois. Como substituto, Eráclio escolheu o monge Folcuíno, consagrado em Colônia, no dia 25 de dezembro de 965. Voltaremos mais adiante para analisar a atuação desse novo abade em Lobbes e os conflitos desencadeados. Mas antes, é preciso fazer uma breve digressão para entender sua trajetória até chegar a Liège.

\section{Folcuíno, oblato de Saint-Bertin de Saint-Omer (948-965)}

Proveniente de uma importante família aristocrática - seu pai descendia de Carlos Martel, um dos prefeitos de palácio mais ilustres do século VIII -, Folcuíno nasceu por volta de 940 na Lotaríngia (a localização exata não é conhecida, embora muito se especule que tenha sido na Diocese de Liège), e foi batizado por Ratério algum tempo depois (DIERKENS, 2013, p. 289-290). Muito jovem, em 948, tornou-se oblato na abadia de Saint-Bertin de Saint-Omer, situada na França Ocidental, junto à Diocese de Thérouanne (representada na imagem 3). Ela era considerada um centro cultural de excelência, tendo contribuído para a formação monástica de Folcuíno.

O desenvolvimento dessa abadia esteve ligado à atuação dos condes de Flandres, em especial de Arnulfo I, o Grande. Para reforçar sua autoridade e prestígio, 


\section{O poder na Idade Média}

Os escritos episcopais e monásticos enquanto vestígios das movimentações políticas e sociais de Folcuíno de Lobbes (935-990) e Ratério de Verona (890-974) ele estabeleceu o controle sobre vários monastérios do condado, declarando-se abade laico (UGÉ, 2005, p. 4). Isso ocorreu em Saint-Pierre de Ghent, em 918, em Artois, em 932, e em Saint-Bertin, em 933. Arnulfo também se envolveu com algumas reformas beneditinas locais, e, embora esses processos tenham tido como resultados posteriores o desenvolvimento de novas disciplinas e costumes monásticos, exemplificados pela separação de cônegos e monges e o fim do abaciado laico, não podemos perder de vista que as relações políticas cumpriram igualmente um papel fundamental. Geraldo de Brogne, por exemplo, foi um eminente reformador, cuja atuação nas abadias estava diretamente ligada aos anseios de Arnulfo.

Desse modo, a entrada desse monge em Saint-Bertin, em 944, se deve, em grande medida, aos anseios do conde por uma reforma que criaria "condições apropriadas para a adequada celebração do culto, os serviços de oração para a família condal e a comemoração dos antepassados do conde" (VANDERPUTTEN, 2013, p. 48$)^{12}$. Em suma, a reforma em Saint-Bertin não foi um movimento radical de separação e autonomia do mundo monástico em relação aos laicos. Pelo contrário, era Arnulfo quem apontava os nomes dos abades mais adequados, mantendo seu controle pessoal sobre o estabelecimento.

As medidas tomadas por ele a partir de 944, porém, não foram amplamente aceitas pela comunidade monástica, pois certos monges, reagindo à sua dominação, procuraram refúgio na Inglaterra (MORELLE, 2010, p. 57). Outro elemento revelador do momento instável do monastério é a ausência de abaciados duradouros. Os violentos conflitos de sucessão explicam o fato de Arnulfo ter precisado nomear cinco

\footnotetext{
${ }^{12}$ No original: "creating appropriate conditions for the adequate celebration of the cult, prayer service for the comital family, and commemoration of the count's ancestors".
} 


\section{O poder na Idade Média}

Vitor Boldrini

abades, transcorridos apenas 17 anos do início de suas intervenções.

Conhecendo esse cenário conturbado pelo qual passava Saint-Bertin, podemos compreender as razões do abade Adolfo, eleito pelo conde Arnulfo em 4 de abril de 961, ter convocado Folcuíno para escrever um texto que pudesse reconstituir a união fraturada dos monges. A obra também reuniu uma coleção dos principais documentos presentes nos arquivos do monastério, com o intuito de determinar, de modo mais preciso, a demarcação dos seus bens e direitos, conferindo aos monges, assim, um instrumento de afirmação e legalidade perante outros agentes sociais. A Gesta abbatum Sithiensium foi composta e publicada por Folcuíno, em 962:

Neste livro de atos dos abades da comunidade monástica de Saint Bertin são publicadas as doações relativas às possessões concedidas pelos fiéis a este local sagrado, acompanhadas do registro das cartas... se alguém estiver curioso para investigar as possessões deste local, basta consultá-lo (HOLDEREGGER, 1881, p. 607-608) ${ }^{13}$.

O trecho acima aponta a motivação central do texto, que é o seu uso enquanto instrumento de administração, de modo a facilitar as pesquisas, não apenas sobre as propriedades, mas também em relação à história monástica, já que ele relata, desde a fundação no período merovíngio, as sucessões de abades. Todavia, a descrição da evolução da abadia não é feita de modo uniforme: o autor mobiliza outras formas textuais, como hagiografias, polípticos e suas próprias reflexões historiográficas sobre

\footnotetext{
${ }^{13}$ No original: "In hoc codice gesta abbatum Sithiensis cenobii depromere cupientes vel possessionum traditiones, quae a fidelibus sub uniuscuiusque illorum tempore sacro huic loco cum cartarum inscriptione sunt concessae... si forsan quis istius loci possessionum investigandarum fuerit avidus, ad hunc recurrat".
} 


\section{O poder na Idade Média}

Os escritos episcopais e monásticos enquanto vestígios das movimentações políticas e sociais de Folcuíno de Lobbes (935-990) e Ratério de Verona (890-974)

as condições sociopolíticas. O documento, então, mescla fontes históricas com elementos narrativos, um modo de Folcuíno construir sua maneira particular de elaborar a história de Saint-Bertin. Ao fazer isso, ele traçou as origens contemporâneas da vida monástica, e mostrou que o serviço contínuo por Deus até o presente constitui o seu apoio legal, espiritual e social (VANDERPUTTEN, 2004, p. 76).

A pedido do abade, Folcuíno não redigiu um documento para ser guardado no convento e utilizado como objeto meramente litúrgico. Na verdade, essa fonte foi uma resposta à situação turbulenta do monastério, tendo como objetivo central sistematizar uma definição mais clara da identidade de Saint-Bertin e de seus monges. Alguns autores não hesitam em defini-la enquanto uma ferramenta de propaganda, por adotar um estilo de escrita pragmático (MORELLE, 2010, p. 58, 2010; UGÉ, 1996, p. 897). Qualquer que seja a definição adotada, a composição da Gesta abbatum Sithiensium e a sua forma final devem ser postas em estreita conexão com o cenário de um monastério que buscava se reivindicar enquanto um espaço de poder particular. Assim, a tentativa de Saint-Bertin de se reorganizar mais sistematicamente, fornecendo para tanto contornos claros e estáveis relativos às suas origens históricas e às condições no presente, são elementos reiterados no último parágrafo do texto:

Eu [Folcuíno] completei o que vós ordenastes, piedoso e amado senhor e pai Adolfo [abade de Saint-Bertin], reunindo neste livro as doações feitas pelos fiéis, acompanhadas das respectivas cartas, assim como os atos dos abades, desde o primeiro, o fundador deste local, Saint-Bertin, até o último. (HOLDEREGGER, 1881, p. 632) ${ }^{14}$.

\footnotetext{
${ }^{14}$ No original: "Explevi iam, ... quae iusseras, domine et beatissime necnon et amantissime pater Adalolfe, comprehendens in uno codice traditiones fidelium cum kartis earum necnon et gesta abbatum ab ipso primo loci huius structore domno Bertino abbate usque ad ultimum".
} 


\section{O poder na Idade Média}

Vitor Boldrini

\section{As disputas pela abadia de Lobbes entre Folcuíno e Ratério (968-973)}

Em 968, Ratério foi afastado pela terceira e última vez do Bispado de Verona, e logo retornou para a Lotaríngia, onde gozava ainda de uma excelente reputação junto aos monges de Lobbes. Mas, dessa vez, ele não pôde assumir livremente a função abacial: em 965, apenas três anos após ter finalizado a Gesta abbatum Sithiensium, Folcuíno, pelo prestígio de sua família na região da Diocese de Liège, e pela sua sólida formação beneditina, já havia sido escolhido pelo bispo Eráclio como o novo abade de Lobbes no lugar de Aletrão, deixando assim Saint-Bertin. Diante desse quadro teve início, portanto, uma tensa querela entre o padrinho, que aspirava retomar o posto que the pertencera outrora, e o seu afilhado, que consolidava sua autoridade na nova abadia para a qual foi nomeado.

Num primeiro momento, Folcuíno adotou medidas favoráveis a Ratério: concedeu permissão para que ele recebesse parte dos rendimentos referentes à abbatiola de Saint-Ursmar de Lobbes e à cella de Aulne, ambas ligadas de modos distintos ao monastério de Lobbes (DIERKENS, 1984, p. 127). Entretanto, os objetivos de Ratério eram ainda mais ambiciosos. Em 971, ele invadiu Lobbes e se tornou o novo abade. Obtida por meio da força, a função abacial não foi logo consolidada, pois Folcuíno reagiu imediatamente. Desse modo, o cargo permaneceu em franca disputa até 973, quando Notger, o novo bispo de Liège, que sucedeu Eráclio, reavaliou a situação e conseguiu estabelecer um compromisso entre os dois personagens envolvidos: Folcuíno foi reconduzido ao seu posto de abade de Lobbes, enquanto Ratério aceitou abrir mão do monastério e se contentar com a posse de parte da cella de Aulne (PATZOLD, 2001, p. 88). Notger obteve do imperador Oto II, em 973, um ato 


\section{O poder na Idade Média}

Os escritos episcopais e monásticos enquanto vestígios das movimentações políticas e sociais de Folcuíno de Lobbes (935-990) e Ratério de Verona (890-974) capital, que selou o retorno de Folcuíno à sua função e ainda confirmou a imunidade (immunitas) e a proteção (defensio) imperial em proveito da abadia (DIERKENS, 2013, p. 292).

Os eventos posteriores ao conflito sugerem que Lobbes entrou num período de relativa estabilidade e prosperidade. Um ato pontifical enviado pelo papa João XV, no dia 1 de fevereiro de 990, ainda quando Folcuíno estava à frente do monastério, reiterou o poder dos seus abades: "E concedemos aos abades desse monastério o uso do anel dourado, das sandálias e das túnicas subdiaconais para a celebração da missa, assim como o poder de se ligar e de se isentar antecipadamente da autoridade de seu bispo [de Liège]" (ZIMMERMANN, 1984, p. 592)15. Quanto a Ratério, ele parece ter aceitado o acordo estabelecido, e não reivindicou qualquer outro cargo. Em 25 de abril de 974, já com mais de 80 anos, ele faleceu em Namur, e foi enterrado na Igreja de Saint-Ursmer de Lobbes, junto a outros monges a pedido de Folcuíno, o que sem dúvida nos viabiliza afirmar que houve uma reconciliação entre o afilhado e o seu padrinho. Indo além, logo após sua morte, em 16 de setembro de 990, Folcuíno foi enterrado nesta mesma Igreja, e seu túmulo foi colocado ao lado do de Ratério, simbolizando ainda mais que o compromisso parece ter sido eficaz e duradouro (DIERKENS, 2013, p. 293).

\subsection{A produção literária contemporânea em Lobbes}

O conflito, segundo a análise que será feita na sequência, afetou substancialmente a produção das fontes do período. A querela, que opôs Folcuíno a

\footnotetext{
${ }^{15}$ No original: "Et concedimus eiusdem loci abbati annulo aureo ubique et sandaliis in celebratione missae et tunicis subdiaconalibus uti, salva etiam vel praemissa sui episcopi auctoritate potestatem ligandi et solvendi habere".
} 


\section{O poder na Idade Média}

Vitor Boldrini

Ratério, é um bom elemento que ajuda a explicar a recuperação de duas tradições distintas sobre as origens de Lobbes. Vimos que, durante sua prisão em Pávia, Ratério compôs a Vita Ursmari, um documento que exaltou a importância do Santo Ursmar para o desenvolvimento da comunidade monástica.

No entanto, em 968, ele altera completamente a leitura feita a respeito dos primeiros anos de Lobbes. Tendo abandonado definitivamente o Bispado de Verona, Ratério introduz uma nova tradição por meio da Vita Landelini metrica. Este documento afirma que a fundação de Lobbes e de suas dependências não se deve tanto a São Ursmar, mas a São Landelin, que é o primeiro abade de fato (DIERKENS, 1983, p. 248). Essa mudança repentina está ligada à relação estipulada por cada um dos fundadores entre Lobbes e os seus estabelecimentos adjacentes. Enquanto a tradição de São Landelin cita a plena igualdade institucional, a interpretação da fundação de São Ursmari menciona que Lobbes prevaleceu, e as suas igrejas próximas seriam dependências sob o controle do abade. Ora, a retomada por Ratério da tradição de São Landelin, em 968, não é fortuita: é nesse momento que ele retornou para Liège e se instalou em Aulne e na Igreja Saint-Ursmar de Lobbes. Com o intuito de explicitar que tanto a sua cella quanto a sua abbatiola não são dependências de Lobbes, ele evoca uma história da fundação que Ihe convém, ou seja, que comprove sua autonomia em relação ao abade Folcuíno. Isso demonstra, em suma, que a composição por Ratério da Vida Landelini metrica, em substituição à Vita Ursmari, está bastante atrelada ao início da conturbada disputa pela supremacia do monastério.

O mesmo ocorre com uma obra de Folcuíno escrita no período, embora adote um argumento contrário. Não é por acaso que ele, como resposta à exaltação de São Landelin por Ratério, resolveu reforçar o culto ao Santo Ursmar por meio da Vita 


\section{O poder na Idade Média}

Os escritos episcopais e monásticos enquanto vestígios das movimentações políticas e sociais de Folcuíno de Lobbes (935-990) e Ratério de Verona (890-974) Ursmari, originalmente escrita pelo seu padrinho, mas redigindo ele próprio uma nova versão, conhecida como Miracula Ursmari (DOLBEAU, 2005, p. 202). A presença de duas distintas explicações sobre as origens de Lobbes e seus arredores por volta de 970 é um reflexo da querela entre Folcuíno e Ratério, que buscaram, pela recuperação das tradições históricas, transmitir a outros agentes sociais, entre eles a comunidade monástica local, visões opostas acerca do monastério, cada qual mais vantajosa para os seus respectivos interesses políticos.

O embate, portanto, encontrou ecos na produção literária: enquanto o primeiro buscou consolidar uma história na qual, por intermédio da valorização do Santo Ursmar, o monastério prevalecesse sobre os estabelecimentos vizinhos, o outro tentou enfatizar, por meio da tradição vinculada ao Santo Landelin, que Aulne e a Igreja Saint-Ursmar gozavam de liberdade, não devendo, por isso, pagar qualquer tributo, e nem se assujeitar a Lobbes. Consolidar uma dessas visões parecia ser importante para ambos. Folcuíno, o então abade, priorizava uma interpretação histórica que fosse mais favorável ao desenvolvimento contemporâneo do monastério, enquanto Ratério privilegiava um argumento histórico em prol da extensão das suas mais novas cella e abbatiola.

O culto ao Santo Ursmar não foi a única atividade literária de Folcuíno durante o tempo em que esteve em Lobbes. Entre 968 e 980, ele redigiu a Gesta abbatum Lobiensium. A obra também deve ser analisada tendo em vista os atritos com o seu padrinho. No entanto, em virtude do longo tempo transcorrido até ela ser finalizada seis anos após a morte de Ratério -, acabou por englobar eventos mais amplos ligados à história e ao desenvolvimento desse monastério.

A elaboração do texto está conectada ao documento escrito por Folcuíno em 


\section{O poder na Idade Média}

Vitor Boldrini

Saint Bertin e analisado anteriormente, a Gesta abbatum Sithiensium. Ambas as fontes celebram a gloriosa e conturbada história de cada comunidade monástica. Elas compartilham um objetivo central, a edificação de uma identidade histórica por meio da reconstrução do passado dos monastérios, moldando, assim, formas de memória comunal e social. Entretanto, a Gesta abbatum Lobiensium assume um caráter inteiramente narrativo. Vimos que o texto redigido em Saint-Bertin misturou diversos gêneros textuais, como hagiografias, documentos diplomáticos e cartas. Nessa nova fonte, Folcuíno mantém o estilo descritivo do início ao fim, o que expressa um cuidado particular para conferir maior precisão às evoluções de Lobbes. Ao fazer isso, ele visou reforçar o prestígio desse local e fortalecer sua posição como abade, criando uma leitura específica que o favorecesse. A escrita da obra, portanto, era um componente indispensável para que os monges se organizassem melhor entre si e a identidade monástica fosse mais estruturada.

A maneira de Folcuíno conceber alguns eventos ou personagens da história recente de Lobbes exprimem que a Gesta foi um instrumento que criou uma memória parcial, uma vez que a narrativa selecionou determinadas informações, apresentando-as de um modo que fornecesse uma história coerente e vantajosa para o atual abade. Ao descrever sua nomeação para o posto abacial, Folcuíno sustenta que ela ocorreu "no Dia do Natal" (PERTZ, 1841, p. 9) ${ }^{16}$. Mesmo se estiver correto, esse registro não aconteceu por acaso. Na verdade, o esforço de marcar no livro que sua entrada em Lobbes coincidiu com o aniversário do nascimento de Cristo - uma data com um sentido muito especial -, se explica pela tentativa de indicar que seu abaciado é abençoado por Deus e marca uma transição, uma nova era na história do monastério (RENSWOUDE, 2006, p. 3). Ele ainda recorre ao dia 25 de dezembro para

\footnotetext{
${ }^{16}$ No original: "Folcuinus fit abbas natale Domini".
} 


\section{O poder na Idade Média}

Os escritos episcopais e monásticos enquanto vestígios das movimentações políticas e sociais de Folcuíno de Lobbes (935-990) e Ratério de Verona (890-974)

datar a revolta de Reginaldo III e Balderico, que invadiram a Diocese de Liège numa "gravíssima conspiração" (PERTZ, 1841, p. 15) 17. Relacionar esse acontecimento com a Noite de Natal é um modo de desqualificá-lo, pois expressa que os revoltosos ignoraram as solenidades desse Dia Santo, utilizando a força de forma ilegítima contra a abadia.

Na sequência, Folcuíno não poderia deixar de citar como os monges expulsaram Erluíno em 957, imposto à comunidade monástica pelo bispo Balderico:

Os monges ficaram ainda mais furiosos por causa disso ... Três deles, que se destacavam dos outros em relação à juventude e ao apoio de parentes, atacaram o dormitório à noite com um grande perigo para a ordem e a profissão. Eles arrastaram Erluíno para fora e, levando-o não muito longe da extremidade do claustro, privaram-no dos olhos e cortaram-lhe parte da língua, mas não ao ponto de ele não poder falar (REMBOLD, 2018, p. 73) ${ }^{18}$.

Esse episódio, por ter ocorrido apenas uma década antes de Folcuíno iniciar a redação da Gesta, era ainda um tema muito atual no monastério. Por isso, para construir uma narrativa que congregasse todos os homens de Lobbes, era fundamental que ele indicasse com clareza tal acontecimento, destacando a participação substancial dos monges.

Outro exemplo significativo é o destaque dado aos Imperadores Germânicos.

\footnotetext{
${ }^{17}$ No original: "gravissima conspiratio".

${ }^{18}$ No original: "The monks were even more furious because of this ... Three of them, who stood apart from the others with regard to their youth and the support of their relatives, attacked the dormitory by night with quite great danger to the order and profession. They dragged Erluin out, and having taken him not far from the edge of the cloister, they deprived him of his eyes and cut off part of his tongue, but not to the point that he could not speak".
} 


\section{O poder na Idade Média}

Vitor Boldrini

Além do Ato Imperial de 973, que confirmou a posição de Folcuíno, houve ainda outros dois, compostos em 980 e 988 respectivamente, que reconheceram novamente as possessões de Lobbes e reiteraram o compromisso com sua proteção (SICKEL, 1888, p. 238-239, 445-446). Pela importância dos Imperadores no desenvolvimento da abadia, sua presença na Gesta era obrigatória.

O autor não relata com grande precisão a situação dos reis entre 840 e 950, ou, quando o faz, traça uma imagem bem pejorativa, valendo-se de termos como "sucessão deficiente" (deficiente successione), "paz eclesiástica conturbada" (turbata ecclesiae pax) e "suporte do reino ordenado de modo tenebroso" (firmamento regni posito in formidine) (PERTZ, 1841, p. 61-62).

Por outro lado, o advento da Dinastia Otoniana contrasta esse quadro turbulento, segundo a interpretação de Folcuíno a respeito de Oto I e de seu irmão Bruno de Colônia: “Oto, então poderosíssimo rei austral, governava também a subjugada Itália; seu irmão, Bruno, terá a única e singular glória futura na Igreja de Cristo" (PERTZ, 1841, p. 24) ${ }^{19}$. Assim sendo, a representação dos Imperadores na Gesta, enquanto agentes que finalmente trouxeram paz e estabilidade duradouras à Igreja, deve ser vista em conexão com a ação efetiva desses homens por meio dos documentos diplomáticos, que garantiram uma condição privilegiada para Lobbes e seu abade.

Por fim, um outro aspecto da obra que deve ser sublinhado é a descrição que é feita de Ratério pelo autor. Como mencionado, a redação da Gesta abbatum Lobiensium é contemporânea ao conflito de Folcuíno com seu padrinho. Por isso, o texto reitera a tradição sobre a fundação do monastério que confere um papel

\footnotetext{
${ }^{19}$ No original: "Ottho, tunc potentissimus rex australis, et subactae Italiae tunc imperitabat: cuius frater Bruno unicum et singulare in Christi ecclesia decus futurum".
} 


\section{O poder na Idade Média}

Os escritos episcopais e monásticos enquanto vestígios das movimentações políticas e sociais de Folcuíno de Lobbes (935-990) e Ratério de Verona (890-974) predominante ao Santo Ursmar, em detrimento de Landelin (PERTZ, 1841, p. 57-58).

Em virtude de uma pesquisa meticulosa (DOLBEAU, 1984, p. 373-431), sabemos que a fonte, até ser concluída em 980, passou por algumas notáveis revisões. Por exemplo, Folcuíno empregou inicialmente termos muito depreciativos: "Ratério, por ter manifestado causas superiores de inimizade, colocando-as à frente das obrigações estabelecidas pela filiação do Sagrado Batismo, invadiu o monastério" (DOLBEAU, 1984, p. 423)20; ele sustenta ainda que, em 971, foi obrigado a abandonar Lobbes, “dada uma gravíssima conspiração" (DOLBEAU, 1984, p. 423)²1.

Essa primeira versão foi contemporânea à querela entre ambos. No entanto, tendo em vista o compromisso estabelecido em 973, o texto final de 980 reformulou o primeiro trecho selecionado da seguinte maneira: “Ratério, que priorizará causas de inimizade, invadiu o monastério" (PERTZ, 1840, p. 70)22. A segunda passagem, ao ser transposta para a versão final, excluiu a expressão "gravíssima conspiração".

Desse modo, constatamos que as modificações no texto da Gesta abbatum Lobiensium guardam um evidente nexo com as transformações do contexto de seu autor ao longo do período em que ela foi redigida. Se Folcuíno difamou Ratério num primeiro momento, acusando-o de desonrar o compromisso batismal e tachando-o de conspirador, a versão final se mostra bem menos intransigente. Nela, são tecidos até alguns elogios ao antigo bispo de Verona, com destaque para o estilo de sua rica produção literária (DOLBEAU, 2005, p. 202). Em síntese, a obra foi também um veículo para marcar a reconciliação do abade com seu padrinho e com os demais monges de

\footnotetext{
${ }^{20}$ No original: "Ratherius, ut manifestaret causas superioris imicitiae, postponens eam quae ex babtismo est filiationem locum invadit".

${ }^{21}$ No original: "facta conspiratione pernitosa et gravissima".

${ }^{22}$ No original: "Ratherius ut ostenderet prioris imicitiae causas, locum invadit".
} 


\section{O poder na Idade Média |}

Vitor Boldrini

Lobbes, buscando, por conseguinte, consolidar sua interpretação pessoal da história da abadia, leitura essa que procurou agregar o conjunto da comunidade monástica a partir da concepção de um passado em comum.

\section{Considerações finais}

Este texto buscou conectar as trajetórias de Folcuíno e Ratério, aqui sinteticamente expostas, com algumas das principais obras desenvolvidas por eles. Para tanto, foi essencial precisar como as disputas sociais nas quais estavam envolvidos influenciaram a produção das fontes e os modos delas serem concebidas. Assim, em termos metodológicos, o argumento central do artigo foi apontar para a necessidade de abordar cada documento particular por meio de uma análise crítica bastante densa, que considere o posicionamento dos autores diante de conjunturas sociais e políticas específicas.

A aplicação desses pressupostos viabilizou uma interpretação das fontes que expôs as formas das autoridades de dois eclesiásticos serem constituídas. Ela se contrapõe ao modelo explicativo das "Três Ordens" (DUBY, 1978), que restringiu o papel dos clérigos ao âmbito religioso, tendo sido eles concebidos como agentes que teriam manipulado as ideologias e mentalidades coletivas do período. Conforme sublinhamos ao longo do artigo, Folcuíno e Ratério não buscaram constituir uma Igreja unificada que ditaria o ritmo de toda a sociedade. Antes, eles construíram vínculos favoráveis aos seus interesses pessoais ou às suas comunidades episcopais/monásticas, não hesitando, para tanto, em estabelecer pontos de contato com o mundo secular.

Por esse ângulo, eles desenvolveram estratégias que possibilitaram a legitimação do poder: vimos que Folcuíno compôs as duas Gestae (referentes aos 


\section{O poder na Idade Média}

Os escritos episcopais e monásticos enquanto vestígios das movimentações políticas e sociais de Folcuíno de Lobbes (935-990) e Ratério de Verona (890-974)

monastérios de Saint-Bertin e Lobbes), tendo como objetivos a sua afirmação perante os demais monges e a consolidação política desses dois estabelecimentos, em momentos em que ambos estavam fortalecendo suas identidades e demarcando mais claramente suas possessões e seus posicionamentos perante a sociedade. Ratério, por sua vez, produziu textos cujo intuito principal era justificar suas atribuições, fossem elas vinculadas aos bispados de Liège ou de Verona, ou ao abaciado de Lobbes. Em suma, "a memória, a escrita e o exercício da autoridade estavam inextricavelmente unidos" (BERKHOFER, 2004, p. 7) ${ }^{23}$.

Autoridade esta cuja solidificação era construída de modo muito complexo. Ela dependia bastante de relações interpessoais ou, como defendem alguns historiadores, de "redes pessoais", definidas como "o conjunto das relações que um indivíduo entretém com outras pessoas que estão em contato com ele, considerando também as relações que não dependem do referido indivíduo" (ROSÉ, 2008, p. 363)²4. Nesse sentido, explicamos, por exemplo, a nomeação de Ratério como bispo de Liége, em 953: ele estava de fato muito próximo dos Imperadores Otonianos, que tinham o poder de investir os ocupantes dessa dignidade. Todavia, tais relações eram permeáveis e se transformavam muito rapidamente. Assim, Oto II não hesitou em confirmar, em 973, que o abade de fato de Lobbes era Folcuíno, e não Ratério.

Isso significa dizer que as posições políticas mais importantes do período não eram estabelecidas de maneira duradoura, devendo ser elas permanentemente reconhecidas "pelos que não fazem parte das elites, pelos iguais e por autoridades

\footnotetext{
${ }^{23}$ No original: "Memory, writing, and authority were inextricably joined".

${ }^{24}$ No original: “l'ensemble des relations qu'un individu particulier entretient avec d'autre personnes qui sont en contact direct avec lui, tout en prenant également en compte les relations qui ne dépendent pas de l'individu concerné".
} 


\section{O poder na Idade Média}

Vitor Boldrini

legitimadoras" (BOUGARD; BÜHRER-THIERRY; LE JAN, 2013, p. 1082)25. Nessa perspectiva, o exercício do poder não ocorria em territórios cujos limites estariam bem definidos. Na realidade, as fronteiras dos locais onde cada indivíduo efetuava sua respectiva dominação eram porosas, e assim os agentes sociais se envolviam de formas distintas com o espaço.

Por isso, a afirmação política, tanto de Folcuíno quanto de Ratério, decorria diretamente das suas constantes circulações e das (re)configurações das suas mais diversas relações pessoais. Este último, inclusive, além de gozar de um duplo estatuto (episcopal e monástico), foi bispo em duas distintas dioceses (Verona e Liège), embora tal tipo de transferência tenha sido proibido pelo Concílio de Nicéia de 325, visto como "propenso ao abuso, por incitar a ambição e o carreirismo" (ROBERTS, 2019, p. $120)^{26}$.

O fato de acoplar os discursos presentes nas obras de Folcuíno e de Ratério com suas práticas sociais propiciou a verificação de alguns traços relativos às movimentações políticas desses dois eclesiásticos, que se mostraram presentes diante de situações nas quais as relações de dominação eram moldadas. O estudo desenvolvido, enfim, constatou que interpretar o século $X$ a partir da separação de categorias contemporâneas, como "Igreja", "Sociedade" e "Estado", pode distorcer nossa leitura sobre os modos como os poderes foram concebidos, num período de estreita imbricação entre os valores cristãos e as estruturações das autoridades políticas.

\footnotetext{
${ }^{25}$ No original: “La position élitaire n'est jamais définitivement acquise et suppose d'être reconnue à la fois par ceux qui ne font pas partie de l'élite, par les égaux ou les pairs et, enfin, par l'autorité légitimante".

${ }^{26}$ No original: "it was ripe for abuse and smacked of worldly ambition and careerism".
} 


\section{O poder na Idade Média}

Os escritos episcopais e monásticos enquanto vestígios das movimentações políticas e sociais de Folcuíno de Lobbes (935-990) e Ratério de Verona (890-974) Referências bibliográficas

\section{- Fontes editadas}

FOLCUÍNO DE LOBBES. Gesta abbatum Lobiensium. In: PERTZ, Georg Heinrich (ed.). Monumenta Germanice Historica, Scriptores IV, 1841, p. 52-74.

FOLCUÍNO DE LOBBES. Gesta abbatum Sithiensium. In: HOLDER-EGGER, Oswald (ed.). Monumenta Germanice Historica, Scriptores XIII, 1881, p. 600-635.

HENDERSON, F. Ernest. Select Historical Documents of the Middle Ages. London: George Bell and Sons, 1910.

RATÉRIO DE VERONA. Praeloquia. In: REID, Peter (ed.). Corpus Christianorum, 46A, 1984, p. 3-196.

RATÉRIO DE VERONA. Phrenesis. In: REID, Peter (ed.). Corpus Christianorum, 46A, 1984, p. $197-218$.

RATÉRIO DE VERONA. Vita S. Ursmari. In: DOLBEAU, François (ed.). "Scribere sanctorum gesta": Recueil d'études d'hagiographie médiévale offert à Guy Philippart, 2005, p. 181 207.

REID, Peter. The Complete Works of Rather of Verona. Binghamton: Center for Medieval and Early Renaissance Studies, 1991.

SICKEL, Thomas (ed.). Diplomata Ottonis II et Ottonis III. In: Monumenta Germanice Historica, Die Urkunden der deutschen Könige und Kaiser, 1888-1893.

WEIGLE, Fritz (ed.). Die Briefe des Bischofs Rather von Verona. In: Monumenta Germanice Historica, Die Briefe der deutschen Kaiserzeit 1, 1949.

ZIMMERMANN, Harald (ed.). Papsturkunden 896-1046. Tomo 1: 896-996, 1984-1985.

\section{- Estudos}

AMANN, Émile; DUMAS, Auguste. L'Église au pouvoir des laïques, 888-1057. Evreux: Bloud \& Gay, 1945. 


\section{O poder na Idade Média}

Vitor Boldrini

BERKHOFER, Robert F. Day of Reckoning: Power and Accountability in Medieval France. Philadelphia: University of Pennsylvania Press, 2004.

BIHRER, Andreas; BRUHN, Stephan. Bischöfe und ihre Diözesen im nachkarolingischen ostfränkisch-deutschen Reich (850-1100). Berlin : Walter de Gruyter, 2019.

BOUGARD, François; LE JAN, Régine. Hiérarchie et stratification sociale dans l'Occident Médíéval (400-1100). Turnhout: Brepols, 2008.

BOUGARD, François; BÜHRER-THIERRY, Geneviève; LE JAN, Régine. Les élites du haut Moyen Âge. Identités, stratégies, mobilité. In: Annales. Histoire, Sciences Sociales, vol. 68, 2013, p. 1079-1112.

BOUGARD, François; DEPREUX, Philippe; LE JAN, Régine. Compétition et sacré au haut Moyen Âge : entre médiation et exclusion. Turnhout: Brepols, 2015.

DIERKENS, Alain. La production hagiographique à Lobbes au Xe siècle. In: Revue Bénédictine, vol. 93, 1983, p. 245-259.

Abbayes et chapitres entre Sambre et Meuse: VIle-Xle siècles: contribution à I'histoire religieuse des campagnes du haut Moyen Âge. Sigmaringen: J. Thorbecke, 1985.

. Notger, Folcuin et Rathier. L'abbaye de Lobbes et les évêques de Liège à la fin du Xe siècle. In: KUPPER, Jean-Louis; WILKIN, Alexis. Évêque et prince. Notger et la Basse- Lotharingie aux alentours de I'an Mil. Liége: Presses Universitaires de Liège, 2013, p. 271-294.

DOLBEAU, François. Ratheriana I. Nouvelles recherches sur les manuscrits et l'oeuvre de Rathier. In: Sacris Erudiri, n. 27, 1984, p. 373-431.

. Ratheriana II. Enquête sur les sources des Praeloquia. In: Sacris Erudiri, n. 28, 1985, p. 511-556.

- Ratheriana III. Notes sur la culture patristique de Rathier. In: Sacris erudiri, n. 29, 1986, p. 151-221.

. La diffusion de la "Vita S. Ursmari" de Rathier de Vérone. In: Recueil d'études d'hagiographie médiévale offert à Guy Philippart. Turnhout: Brepols, 2005, p. 181207. 


\section{O poder na Idade Média}

Os escritos episcopais e monásticos enquanto vestígios das movimentações políticas e sociais de Folcuíno de Lobbes (935-990) e Ratério de Verona (890-974)

. Pour mieux lire les Praeloquia de Rathier. In: Mélanges Pascale Bourgain. Turnhout: Brepols, 2016, p. 133-151.

DUBY, Georges. Les trois ordres ou l'imaginaire du féodalisme. Paris: Gallimard, 1978.

GUERREAU, Alain. L'Avenir d'un passé incertain. Paris: Seuil, 2001.

HAARLÄNDER, Stephanie. Eine Quellengattung zwischen Hagiographie und Historiographie, untersucht an Lebensbeschreibungen von Bischöfen des Regnum Teutonicum im Zeitalter der Ottonen und Salier. Stuttgart: Anton Hiersemann, 2000.

IOGNA-PRAT, Dominique. La Maison Dieu. Une histoire monumentale de l'Église au Moyen Age, v. 800-v. 1200. Paris: Le Seuil, 2006.

JÉGOU, Laurent; PANFILI, Didier. L'Europe seigneuriale 888-1215. Paris: Armand Colin, 2018.

KUPPER, Jean-Louis. Art. Folcuin, Abt von Lobbes (um 935-990). In: Lexikon des Mittelalters, vol. 4, 1989, p. 608.

KURDZIEL, Emilie. La vie est un sport de combat. L'agon dans l'oeuvre de Rathier de Vérone (v. 899-974). In: BOUGARD, François; LE JAN, Régine; LIENHARD, Thomas. Agôn. La compétition, Ve-XIle siècle. Turnhout: Brepols, 2012, p. 311-332.

LAUWERS, Michel. L'Église dans l'Occident médiéval: histoire religieuse ou histoire de la société? Quelques jalons pour un panorama de la recherche en France et en Italie au XXe siècle. In: Mélanges de l'École française de Rome. Moyen-Age, tomo 121, n. 2, 2009, p. 267-290.

MAZEL, Florian. Monachisme et aristocratie aux Xe-Xle siècles. Un regard sur I'historiographie récente. In: VANDERPUTTEN, Steven. Ecclesia in medio nationis: Reflections on the Study of Monasticism in the Central Middle Ages. Leuven: Leuven University Press, 2011, p. 47-75.

MORELLE, Laurent. Diplomatic Culture and History Writing: Folcuin's CartularyChronicle of Saint Bertin. In: MAXWELL, Robert (ed.). Representing History, 900-1300. Art, Music, History. The Pennsylvania State University, 2010, p. 53-65.

PARISSE, Michel. L'évêque d'Empire au Xle siècle. L'exemple lorrain. In: Actes des 


\section{O poder na Idade Média}

Vitor Boldrini

congrès de la Société des historiens médiévistes de l'enseignement supérieur public, 14e congrès, Poitiers, 1983, p. 95-105.

PATZOLD, Steffen. Konflikte im Kloster: Studien zu Auseinandersetzungen in monastischen Gemeinschaften des ottonische-salischen Reichs. Husum: Matthiesen Verlag, 2000.

"...inter pagensium nostrorum gladios vivimus". Zu den "Spielregeln" der Konfliktführung in Niederlothringen zur Zeit der Ottonen und frühen Salier. In: Zeitschrift der Savigny-Stiftung für Rechtsgeschichte: Germanistische Abteilung, n.118, 2001, p. 58-99.

REMBOLD, Ingrid. History and (Selective) Memory: Articulating Community and Division in Folcuin's Gesta abbatum Lobiensium. In: SCREEN, Elina; WEST, Charles. Writing the Early Medieval West. Cambridge: Cambridge University Press, 2018, p. 64-79.

RENSWOUDE, Irene van. Time is on our side. Liturgical time and political history in the Chronicle of Lobbes. In: Forschungen zur Geschichte des Mittelalters, vol. 12, 2006, p. 323- 344.

- The sincerity of fiction. Rather and the quest for self- knowledge. In: Forschungen zur Geschichte des Mittelalters, vol. 15, 2010, p. 309-334.

ROBERTS, Edward. Bishops on the Move. Rather of Verona, Pseudo-Isidore, and Episcopal Translation. In: The Medieval Low Countries, n. 6. Turnhout: Brepols, 2019, p. 117-138.

ROSÉ, Isabelle. Construire une société seigneuriale: itinéraire et ecclésiologie de I'abbé Odon de Cluny (fin du IXe-milieu du Xe siècle). Turnhout: Brepols, 2008.

SCHALLER, Hans Martin. Art. Rather, Bischof von Verona und Lüttich († 974). In: Lexikon des Mittelalters, vol. 7, 1995, p. 457-458.

SCHLOCHTERMEYER, Dirk. Bistumschroniken des Hochmittelalters. Die politische Instrumentalisierung von Geschichtsschreibung. Paderborn: Schöningh, 1998.

UGÉ, Karine. Creating a usable past in the tenth century. Folcuin's Gesta and the crises at Saint-Bertin. In: Studi medievali, n. 37, 1996, p. 887-903.

Creating the Monastic Past in Medieval Flanders. Nova York: Boydell \& 


\section{O poder na Idade Média}

Os escritos episcopais e monásticos enquanto vestígios das movimentações políticas e sociais de Folcuíno de Lobbes (935-990) e Ratério de Verona (890-974) Brewer, 2005.

VANDERPUTTEN, Steven. Literate Memory and Social Reassessment. In: Mediaevistik, t. 17, 2004, p. 65-94.

Monastic Reform as Process: Realities and Representations in Medieval Flanders, 900-1100. Ithaca-London: Cornell University Press, 2013.

VIGNODELLI, Giacomo. "Milites Regni": aristocrazie e società tripartita in Raterio da Verona. In: Bullettino dell'Istituto storico italiano per il medioevo, n. 109, 2007, p. 97-150.

Imagens

Imagem 1: GIMENO. Questions Internationales. 2011

Imagem 2: ROSÉ. Construire une société seigneuriale: itinéraire et ecclésiologie de l'abbé Odon de Cluny (fin du IXe-milieu du Xe siècle). 2008.

Imagem 3: UHRMACHER. De la mer du Nord à la Méditerranée. Francia Media, une région au coeur de l'Europe (c. 840-c. 1050). 2011.

Imagem 4: VIGNODELLI. "Milites Regni": aristocrazie e società tripartita in Raterio de Verona. 2007. 